\title{
Using Balanced Scorecard (BSC) approach to improve ergonomics programs
}

Fernandes, Marcelo Vicente Forestieri

Tersso Design, Rua Treze de maio, 1389, 01327-001, São Paulo, SP, Brasil

\begin{abstract}
The purpose of this paper is to propose foundations for a theory of using the Balanced Scorecard (BSC) methodology to improve the strategic view of ergonomics inside the organizations. This approach may help to promote a better understanding of investing on an ergonomic program to obtain good results in quality and production, as well as health maintenance. It is explained the basics of balanced scorecard, and how ergonomists could use this to work with strategic enterprises demand. Implications of this viewpoint for the development of a new methodology for ergonomics strategy views are offered.
\end{abstract}

Keywords: Ergonomics, Balanced Scorecard, Methodology, Strategy 


\section{Introduction}

This article has the objective to provide a new approach of implementation an ergonomic program in any company, using the Balanced Scorecard (BSC) methodology as a strategic tool.

The Balanced Score Card was developed by Drs. Robert Kaplan and David Norton giving managers a balanced view of organizations working with others perspectives besides the classical financial measurements.

As defined by the Balanced Scorecard Institute[1] it is a "strategic planning and management system that is used extensively in business and industry, government, and nonprofit organizations worldwide to align business activities to the vision and strategy of the organization, improve internal and external communications, and monitor organization performance against strategic goals."

This methodology suggests using targets in four perspectives:

1) Business Process Perspective: This measure allows knowing how their processes are running conform to clients requirements. It is aligned to the mission purpose;

2) Customer Perspective: Here is monitored the client satisfactions in guarantee of attend their needs and their expectations.

3) Learning \& Growth Perspective: This perspective helps to provide a continuous learning and training practices to improve the business culture and corporate self-improvement.

4) Financial Perspective: More than just the classical view of financial measures, this perspective aligned with others perspectives shows how is the company working to get trough the financial targets.

Using this new vision inside an ergonomic program could help ergonomists to improve their own services to attend internal clients according to a macro enterprise strategy.

\section{Practice Innovation}

Using the BSC to manage an ergonomic program will help to define best practices inside each company and help ergonomists to participate more in concept projects and minimize the gap that could exist between managers and the health problems.

An example of this implementation should suggests working with some indicators inside these four perspectives and how they can be linked.

\section{1) Learning \& Growth Perspective}

A continuous learning process should be implemented inside the team, and the ergonomist need to know the basic laws applied to each country and the specifics practices for each company in safety and health are vital. Also, participating in seminars, congresses, associations and other study groups are strongly necessary to improve our experience, helping to share problems and casual solutions.

\section{2) Business Process}

Supported by the good content and experience acquired, defining best practices should be easier. It could be best defined when and how to attend for each demand and how to treat them. In this case, other tools could be used to perform internal process, like PDCA (Plan, Check, Do, Act).

\section{3) Customer Perspective}

Usually customers need to have a very fast solution for their demand, and more than that something reliable, easy to understand, to implement and with low costs. These could be reached with a perfect internal organization and domain of technical and adjacent knowledge.

\section{4) Financial Perspective}

The ergonomic department should use specific amount of investment dispended by the company to ensure their payback. These payback is usually show in less work time loss, better quality in global products and services, and, certainly, less work-related injuries and diseases. 


\section{Conclusion}

We can observe that we have a complete and infinite cycle that could help the company to see the ergonomic department as important as a R\&D (Research and department) for strategic purposes also, and not only to prevent work-related diseases.

These could change company views of Ergonomics, specially in Brazil, where a program appear as reducing costs and not as an investments on quality and production.

\section{References}

[1] The Balanced Scoredcard Institute - Balanced Scorecard basics http://www.balancedscorecard.org/BSCResources/AbouttheBalanc edScorecard/tabid/55/Default.aspx - Accessed on September, 2011. 